\title{
Role of plasma ascorbic acid in nasal allergy- a review
}

\section{Manish Munjal*, Atul Singh, Ajit Singh Khurana, Shubham Munjal, Arnav Mehta, Khyati Shukla, Gurkaran Waraich}

Department of ENT, Dayanand Medical College Ludhiana, Punjab, India

Received: 06 July 2020

Revised: 18 August 2020

Accepted: 07 September 2020

\section{*Correspondence:}

Dr. Manish Munjal,

E-mail: manishmunjaldr@yahoo.com

Copyright: (c) the author(s), publisher and licensee Medip Academy. This is an open-access article distributed under the terms of the Creative Commons Attribution Non-Commercial License, which permits unrestricted non-commercial use, distribution, and reproduction in any medium, provided the original work is properly cited.

\section{ABSTRACT}

Ascorbic acid plays a pivotal role in common cold and allergic rhinitis by affecting the innate and adaptive immunity It antagonizes mediators of allergic rhinitis like histamine, prostaglandins etc. It also maintains the normal redox potential of the cells preventing bonding of antibody to antigen. It helps in stress conditions and has stimulatory effect on interferon synthesis. The present study was undertaken to study the role of plasma ascorbic acid in patients suffering from nasal allergy.

Keywords: Calcitonin gene-related peptide, Granulocyte-macrophage colony-stimulating factor, Immunoglobulin, Interleukins, Leukotrienes, Platelet activating factor, Substance

\section{INTRODUCTION}

Ascorbic acid has been implicated in various physiological and biochemical interactions in human body including its role in cellular oxidation-reduction, collagen synthesis, as cofactor in various metabolic pathways, in stress conditions, common cold and allergic conditions.

\section{REVIEW OF LITERATURE}

\section{Historical background}

The importance of vitamin-C traces back to fifteenth century when during a voyage of Vasco-da-Gama around the cape of good hope there was a mass casualty because of general weakness, swelling of gums, loosening of teeth and small hemorrhages in the skin.

In 1535, Jacques Cartier's men were stricken with this disease during their explorations in Canada. In 1747, Lind, a British naval surgeon treated these scorbutic sailors with fruit juices. The disease and its control was first published by him in 1757 in "Treatise on Scurvy".

The dietary origin of the disease was confirmed experimentally in guinea pigs by Holst and Frolich confirmed the dietary origin of the disease experimentally in guinea pigs in 1907 and the deficient factor was among the first to receive the designation of vitamin.

Szent Gyorgi 1928 isolated a substance from adrenal gland called "hexuronic acid".

The isolation of crystalline vitamin $\mathrm{C}$ was first done in 1932 by king and Waugh. Haworth and Hirst in 1933 established the structural formula and synthesized ascorbic acid.

Since then ascorbic acid has been implicated in various physiological and biochemical interactions in human body including its role in cellular oxidation-reduction, collagen synthesis, as cofactor in various metabolic pathways, in stress conditions, common cold and allergic conditions. 


\section{Role of ascorbic acid}

The role ascorbic acid plays in common cold and allergic rhinitis has been stressed by various scientists from time to time.

Raffel and Medison in 1938 demonstrated that ascorbic acid influences antibody response to specific antigenic stimulation in cases of allergic rhinitis. ${ }^{1}$

Goldsmith demonstrated lower levels of ascorbic acid in 29 cases of allergic rhinitis and that the manifestations could be ameliorated with vitamin $\mathrm{C}$ supplementation. ${ }^{2}$

Edward et al 1951 reported that the normal human blood plasma ascorbic acid levels range between 0.7 to 1.2 $\mathrm{mg} / 100 \mathrm{ml}$ and if this level is between 0.4 to $0.7 \mathrm{mg} \%$ it is mild deficiency. ${ }^{3}$ Plasma ascorbic acid below $0.4 \mathrm{mg} \%$ is taken as severe deficiency. On high dietary intake, plasma level may rise to $2.0 \mathrm{mg} \%$. Hawk et al stated that the plasma level greater than $0.7 \mathrm{mg}$ per $100 \mathrm{ml}$ can be regarded as normal. ${ }^{4}$

Bellenger and Bellenger found that ascorbic acid, when given in heavy doses i.e. $1 \mathrm{gm} /$ day, assists in decreasing generalized well being but Cook et al in 1959 gave little or no value to it. ${ }^{5,6}$

Mahindra and Mahindra did a study on a series of 35 cases to assess the ascorbic acid levels in plasma and urine during acute stage of allergy. ${ }^{7}$ The mean level of plasma ascorbic acid was $1.4 \mathrm{mg} / 100 \mathrm{ml}$. The study also revealed lower values of plasma levels of ascorbic acid in patients with allergic rhinitis which improved with heavy medication of vitamin $C$. This coincided with subjective and objective improvement of the allergic conditions.

Georgina et al showed in vitro experiments that exposure of cells to ascorbic acid increased their resistance to infection and to mediators of allergic conditions by stabilising lysozomes and preventing cytopathic effect due to release of various enzymes. ${ }^{8}$

It was shown that ascorbic acid had protective effect on histamine induced hypersensitivity.

Wilson and Loh reported that ascorbic acid alters the frequency of toxic and catarrhal complexes. ${ }^{9}$ Utilization of ascorbic acid was significantly increased during symptoms of common cold. The severity of the symptoms was reflected more accurately by changes in plasma than by changes in leucocyte ascorbic acid.

Rao stated that adrenal cortex has high concentration of vitamin C. ${ }^{10}$ Stimulation of the gland causes rapid depletion of vitamin indicating that it is required for stress conditions. Ascorbic acid is also required for maintaining redox potential of the cells and absorption of iron.
Tengerdy et al in 1975 showed that supplementation of normal diets with vitamin $\mathrm{E}$ and vitamin $\mathrm{C}$ enhances $\mathrm{T}$ cell and macrophage dependent antibody response. ${ }^{11}$

Puglisi et al 1976 reported that ascorbic acid acts by antagonising prostaglandin in a dose-dependent manner. $^{12}$

Vallance in 1977 found direct relationships between increasing blood ascorbic acid levels and serum $\mathrm{IgG}$ and $\mathrm{IgM}$ titres, those between $\mathrm{IgG}$ and leucocyte ascorbic acid were statistically significant. ${ }^{13}$ These results showed that ascorbic acid increases IgG and IgM synthesis. Specific immunoglobulin (IgG) levels were affected more than those of non-specific IgM.

Harman et al showed that the age related depression of immunity could be prevented with vitamin $\mathrm{C}$ and Other antioxidants. $^{14}$

Baird et al 1979 conducted a study on 362 individuals and found that ascorbic acid supplemented groups had a 14 to $21 \%$ reduction in total symptoms of allergic episodes recorded. ${ }^{15}$ Ascorbic acid significantly increased the number of 'episode free subjects'. They also found that ascorbic acid breakdown products or metabolites may be more important in prophylaxis than ascorbic acid itself which, therefore, can give variable results. Ascorbic acid also induces a rise in $\operatorname{IgG}$ and IgM levels.

Werner in 1979 stated that supplementation of normal diets with antioxidants produced immune-stimulatory effects. ${ }^{16}$ Their dietary deficiency caused a serious depression of immunity which restores to normal with supplementation of antioxidants. These also enhance the killing capacity of neutrophils. Antioxidants including ascorbic acid have immunostimulatory effects due to an adjuvant property by providing optimal biochemical environment. Antioxidants influence numerous enzymes and membrane processes via sulfhydryl/disulfide exchange reactions. They also emphasized that phagocytes present in the immune reactions, notably the neutrophils and macrophages, generate considerable quantities of oxidants during phagocytosis, such as lipid hydroxides, superoxide, singlet oxygen, hydrogen peroxide, $\mathrm{OH}$ radicals and prostaglandins (via oxidative radical processes). All these substances are potent lymphocyte deactivators. Ascorbic acid is needed for protection of lymphocytes against the inhibitory products of phagocytes. It inhibits prostaglandin synthesis and modulates immune system.

Anah al did a double-blind randomized longitudinal trial on 41 patients and showed that ascorbic acid leads to decrease in number of allergic attacks. ${ }^{17}$

Munjal et al in 1985 studied 60 cases of allergic rhinitis and estimated ascorbic acid levels in their blood and urine and the effect of ascorbic acid supplementation on them. ${ }^{18}$ They found that ascorbic acid level in normal individual 
was $1.93 \mathrm{mg} \%$ in blood and its excretion in urine was $17.43 \mathrm{mg} /$ day. They reported that in acute allergic rhinitis these levels are much low which denotes unsaturated states of body which is again demonstrated by increased utilization. Heavy doses of ascorbic acid were found to be objectively beneficial in allergic rhinitis.

Ascorbic acid helps in blocking the allergic symptoms by reducing the disulphide bonds between the chains of antibody molecules making their binding with antigen impossible. Antibodies seek to match antigens only in the areas where stray free radicals or a relatively oxidizing redox potential exists. The redox state of normal, healthy tissue does not allow the binding of antibody to antigen. When antioxidant, free radical scavenging systems are overwhelmed, inflammatory or hypersensitivity and autoimmune conditions may result. ${ }^{19}$

Schwartz and Weiss confirmed that vitamin C neutralizes free-radicals and suppresses macrophage secretion of superoxide anions. ${ }^{20}$

A study on 20 normal subjects and 20 patients and found that the mean ascorbic acid level in the control group was $4.15 \mathrm{mg} / \mathrm{l}$ while it was $3.4 \mathrm{mg} / \mathrm{l}$ in the acute phase of tonsillitis. Bucca et al showed the beneficial effect of oral administration of $2 \mathrm{gm}$ vitamin $\mathrm{C}$ on allergic responsiveness to inhaled histamines in 16 patients with allergic rhinitis. ${ }^{21}$

High concentration of ascorbic acid in leucocytes and its rapid utilization during infection and phagocytosis suggests its role in immune response. This protective role of ascorbic acid in recurrent infection and allergy is attributed to its stimulatory effect on interferon synthesis and lymphocyte function leading to augmented immune response. $^{22}$

Maderazo et al demonstrated that the antioxidants like vitamin $\mathrm{C}$ 1mprove the polymorphonuclear cells locomotion vis-a-vis placebo. ${ }^{23}$

Blood histamine is significantly depressed in high blood ascorbate level and leucocyte chemotaxis is significantly impaired in low blood ascorbate levels. ${ }^{24}$

Jullinson et al in 1993 showed that the mast cell is an important trigger cell in immediate nasal allergic response. $^{25}$

Bielory and Gandhi 1994 reported a positive effect of vitamin $\mathrm{C}$ in improving white blood cell function and motility with decrease in allergic episodes. ${ }^{26}$

Anderson et al stated that ascorbic acid enhances chemotactic function, neutrophil motility and lymphocyte transformation. $^{27}$

Kodma et al found that vitamin $\mathrm{C}$ infection or infusion treatment induced an increase of plasma glucocorticoid activity with a delay in onset of about two hours assessed in terms of eosinophil count and plasma cortisol concentration. $^{28}$

Schwartz and Weiss in a National Health and Nutrition Survey conducted on 2526 adults between 1971-1974 found the vitamin $\mathrm{C}$ is an important antioxidant that directly neutralized free radicals, suppresses macrophage secretion superoxide anions and is a part of the glutathione peroxidase pathway for repairing oxidative damage to the lipid membrane. ${ }^{20}$ Higher dietary intake and serum concentrations of vitamin $\mathrm{C}$ protects against allergic conditions. Tests of cellular immune function such as neutrophil chemotaxis and phagocytoses, secretory immunoglobulin-A concentrations, and immunoglobulin, were all improved with $1 \mathrm{gm}$ ascorbic acid/day.

\section{Mechanism of allergic rhinitis}

The term allergy as originally coined by Von Pirquet in 1906 was used to indicate the altered response of an individual towards a specific substance resulting from previous experience with that substance. ${ }^{29}$

Hansel studied various clinical presentation or allergic rhinitis. ${ }^{30}$

Coomb and Gell classified the allergic reactions into type I-IV. This simple classification is of use in practice. ${ }^{31}$ If a demonstrable inflammatory reaction takes place minutes after the antibody reaction it is called immediate type reaction. If the reaction can be recognized only after hours or days it's called a 1ate and delayed reaction respectively. The classification is as follows: 1) Humoral immune reactions- Type I (immediate); Type II (immediate); Type III (late) and 2) Cellular immune reactions- Type IV (delayed and T-lynphiocyte mediated).

Type I reactions are of utmost importance for nasal allergy and type III reactions possibly of some significance. Type I reaction (anaphylactic reaction or reaginic hyper sensitivity) is IgE mediated. The antibody is cytophilic, which means that it is attached to the surface of mast cells and basophils by the Fc-fragment. The cells degranulate and liberate chemical mediators. The primary mediators of type I reactions are histamine, slow-reacting substance-A (SRS-A), eosinophil chemotactic factor-A (ECF-A), etc. The secondary mediators are prostaglandins, serotonin, kinins, etc. and the intracellular regulators are cyclic AMP and cyclic GMP. The mediators liberated from mast cells may be preformed and thus act rapidly (e.g. histamine), preformed and slowly eluted from the granule matrix such as heparin or trypsin, or newly synthesized upon release, such as leukotrienes and prostaglandins. These mediators dilate blood vessels, constrict bronchial smooth muscles and stimulate the glands in airways. Chemical mediators produce symptoms in the target organs and 
lead to formation of increased vascular permeability, tissue edema and cellular recruitment. The slowly eluted mediators support reactions not apparent until 4 to 24 hours following mast cell activation. These '1ate-phase' mast cell-mediated reactions produce obstruction in nose and are caused by cellular infiltration. The characteristic cell in the inflammatory reaction is eosinophils.

In type III reaction (immunocomplex reaction) antibody (IgG) antigen complex activates the complement system that is primary humoral mediator of antigen-antibody reactions. It consists of atleast fifteen plasma proteins which interact sequentially producing substances that mediate several functions of inflammation including cell lysis, release of histamine from mast cells and platelets, vascular permeability, contraction of smooth muscles and chemotaxis of leukocytes.

Kay in 1987 described allergic rhinitis as an IgE mediated hypersensitivity disease of mucous membrane of nasal airway characterized by sneezing, nasal discharge and blockage. ${ }^{32}$

Wilson et al demonstrated that histamine provocation of nasal mucosa produces reflex sneezing and marked vasodilation via both $\mathrm{H}_{1}$ and $\mathrm{H}_{2}$ receptors in allergic rhinitis. $^{33}$ There is significant basal levels of free histamine which is between 14 to $65 \mathrm{ng} / \mathrm{ml}$ in patients with allergic rhinitis whereas in controls it is 10 .

Shekhar and Sharan reported that an presence of specific antigen there is an explosive degranulation of mast cells which is responsible for release of histamine and other mediators of anaphylaxis. ${ }^{34}$

White and Kaliner in 1992 stated that the normal subjects the nasal mucosa has 150 lympbocytes and 10-mast cells per millimeter of basement membrane. ${ }^{35}$ Within minutes of exposure the mast cell products such as histamine, $\mathrm{LTC}_{4}, \mathrm{PGD}_{4}, \mathrm{SRS}-\mathrm{A}$, IL etc. are released leading to cardinal symptoms of allergic rhinitis. Mast cells are found near superficial postcapillary venules (which respond with increased vascular permeability), near sensory nerves (which respond by initiating the itch sensation and thus sneeze reflex), and near glands that respond by secretion. Concomitant with the increase in mast cell mediators, an increase in the neuropeptides CGRP, SP and VIP and bradykinin can also be observed. In addition, mast cell activation leads to transcription and/or translation and release of number of cytokines including TNF- $\alpha$, IL-1, IL-2, IL 3, IL-4, IL-5 and IL-6 and GM-CSF. During allergic response, the nose also contains many inflammatory cells that may contribute cytokines to allergic response. Lymphocytes comprise most of the cells in the nasal submucosa. Pruritis and sneezing are induced by sensory $\left(\mathrm{H}_{1}\right)$ nerve stimulation, whereas congestion results from vasodilation. Rhinorrhea can be induced by increased vascular permeability as well as direct glandular secretion. In the nerves contralateral to antigen challenge, rhinnorhea comprises entirely of glandular proteins. This appears to be cholinergically mediated. During the first 30 minutes after allergen challenge, concomitant with an increase in mediators, an enormous increase occurs in plasma proteins albumin and IgG and smaller increase in glandular proteins lysozymes, lactoferrin and secretory IgA in nasal lavage fluids. Thus antigeninduced rhinorrhoea is caused mostly by vascular permeability on the ipsilateral side only and by reflex mediated glandular secretion on both ipsilateral and contralateral side. In addition to histamine, newly generated leukotrienes and bradykinin can induce both vasodilation and increased vascular permeability, whereas leukotrienes can also induce glandular secretion. Both parasympathetic and sensory neurons are stimulated during allergic reactions and several of neuropeptides localized to these neurons increase in nasal secretions after antigen challenge. These neuropeptides SP and VIP are capable of inducing glandular secretions, whereas CGRP, which is localized with SP to sensory fibres, is capable of inducing vasodilation and contributing to congestion. Mast cells derived chemotactic factors as well as PAP, IL-5, and IL8 are probably instrumental in attracting inflammatory cell $g$ into the late-phage reaction. IL-I, IL-6, and TNF- $\alpha$ also probably play a role in inducing inflammation through up regulation of adhesion molecule expression. IL-2 may be important in activating lymphocytes after allergen challenge, providing the message for additional cytokine production. Finally, IL-3, IL-4, IL-6 and IL-10 play a role in promoting mast cell growth and differentiation and in enhancing IgE synthesis. Histamine is the major mediator of the immediate allergic reaction. The late phase reaction is triggered by the release of chemotactic factors from mast cells as well as by the generation and release of inflammatory and chemotactic cytokines.

\section{DISCUSSION}

As is evident from all the above studies, ascorbic acid helps to alleviate allergic rhinitis manifestations by neutralizing free radicals, suppressing macrophage secretion of superoxide anions and repair of damaged lipid membrane. It enhances immunity function such as neutrophils chemotaxis phagocytosis and increases immunoglobulin concentration. It antagonises mediators of allergic rhinitis like histamine, prostaglandins etc. It also maintains the normal redox potential of the cells preventing bonding of antibody to antigen. It helps on stress conditions and has stimulatory effect on interferon synthesis.

\section{CONCLUSION}

Vis a vis the exhaustive research, the role of plasma ascorbic acid in patients suffering from nasal allergy cannot be under estimated. Adequate supplementation with anti-histaminic and steroid therapy serves to alleviate the signs and symptoms of allergic rhinitis. 
Funding: No funding sources

Conflict of interest: None declared

Ethical approval: Not required

\section{REFERENCES}

1. Raffel S, Madison RR. The Influence of Ascorbic Acid on Anaphylaxis in Guinea Pigs. The Journal of Infectious Diseases. 1938:71-6.

2. Munjal KR, Tankwal M, Gogia JS. Estimation of ascorbic acid levels in blood and urine in cases of allergic rhinitis. Indian Journal of Otolaryngology. 1985;37(3):85-6.

3. West ES, Wilbert, Todd WR, Mason HS, Bruggen JTV. Textbook of biochemistry. 4th edn. The Macmillan Company; 1966:831.

4. Hawk PB, Summerson WH. Practicalphysiological chemistry 13th edn (London: J and A Churchill).1226-1243.

5. Ballenger H. Ballenger. M. c.: Chronic hyper-plastic adenoid. Diseases of the Nose Throat and Ear. 1957:294.

6. Cook NR, Albert CM, Gaziano JM, Zaharris E, MacFadyen J, Danielson E, Buring JE, Manson JE. A randomized factorial trial of vitamins $\mathrm{C}$ and $\mathrm{E}$ and beta carotene in the secondary prevention of cardiovascular events in women: results from the Women's Antioxidant Cardiovascular Study. Archives of internal medicine. 2007 Aug 13;167(15):1610-8

7. Mahindra S, Mahindra SK. Study of blood and urinary ascorbic-acid levels in cases of allergic rhinitis. Indian J Otolaryngol. 1967;19(3):130-4.

8. Georgina HW, Bynoe ML, Tyrell DAJ. Trial of ascorbic acid in prevention of colds. BR Med J. 1967;1(5540):603-6.

9. Wilson CW, Loh HS. Common cold and vitamin C. Lancet. 1973;1(7804):638-41.

10. Rao AVSSR: Textbook of Biochemistry, 5th ed. LK \& S publishers, Visakhapatnam. 1988 .5th edition: 198-200.

11. Tengerdy RP, Nockels CF. Vitamin E or Vitamin A protects chicken against E. coli infections. Poult Sci. 1975;54:638-45.

12. Puglisi L, Berti F, Bosiso E, Longiane D, Nicosia S. Ascorbic acid and prostaglandin F2 alpha antagonism on tracheal smooth muscle. PGTX Res NY. Raven Press. 1976;1:503-6 .

13. Vallance S. Relationship between ascorbic acid and seum proteins of immune system. $\mathrm{Br}$ Med $\mathrm{J}$. 1977;2:437.

14. Harman D, Heidrick ML, Eddy DE. Free radical theory of aging: effect of free-radical-reaction inhibitors on the immune response. J Am Geriatr Soc. 1977;25(9):400-7.

15. Baird IM, Hughes RE, Wilson HK, Davies JE, Howard AN. The effects of ascorbic acid and flavonoids on the occurrence of symptoms normally associated with the common cold. Am J Clin Nutr. 1979;32(8):1686-90.
16. Baumgartner WA. Antioxidants, cancer and the immune response. Trace Metals in Health and Disease. 1979 Dec 1:287-305.

17. Anah CO, Jarike LN, Baig HA. High dose ascorbic acid in Nigerian asthmatics. Trop Geogr Med. 1980;32(2):132-7.

18. Munjal KR, Tankwal M, Gogia JS. Estimation of ascorbic acid levels in blood and urine in cases of allergic rhinitis. Indian Journal of Otolaryngology. 1985;37(3):85-6.

19. Cathcart III RF. The vitamin C treatment of allergy and the normally unprimed state of antibodies. Med Hypothes. 1986;21(3):307-21.

20. Schwartz J, Weiss ST. Dietary factors and their relation to respiratory symptoms: the Second National Health and Nutrition Examination Survey. Am J Epidemiol. 1990;132(1):67-76.

21. Bucca C, Rolla G, Oliva A, Farina JC. Effect of vitamin $\mathrm{C}$ on histamine bronchial responsiveness of patients with allergic rhinitis. Ann Allerg. 1990;65(4):311-4.

22. Askarkhodzhaev NA, Tazulakhova EB, Ershov FI. Stimulation of interferon production. Antibiotiki. 1979 Sep 1;24(9):669-72.

23. Maderazo EG, Wornick CL, Hickengbotham N, Jacobs L, Bagvan HN. A randomized trial of replacement antioxidant vitamin therapy for neutrophil locomotry dysfunction on blunt trauma. J Trauma. 1991;31(8):1142-50.

24. Johnston CS, Huang S. Effect of ascorbic acid nutriture on blood histamine and neutrophil chemotaxis in guinea pigs. J Nutr. 1991;121(1):12630.

25. Jullinson S, Holmberg K, Karlsson G, Eneaback L, Pipkorn U. Mast cells and mediators on the nasal mucosa after allegen challenge. Clin Exp Allerg. 1993;23(7):591-9,

26. Bielory R, Gandhi R. Asthma and vitamin C. Ann Allerg. 1994;73(2):89-96.

27. Bielory L, Gandhi R. Asthma and vitamin C. Ann Allerg. 1994;73-8:89-96.

28. Kodama M, Kodama T, Murakami M. Autoimmune disease and allergy are controlled by vitamin C treatment. In vivo (Athens, Greece). 1994;8(2):2517.

29. Von Pirquet C. Allergie. Munchen Med Wchnschr. 1906;53:1457-8.

30. Hansel FK.Vasomotor rhinitis. Journal of the American Medical Association. 1924 Jan 5;82(1):15-7.

31. Coomb RRA, Gell PGH. Clinical aspects of Immunology. 2nd edn. Oxford Blackwell Scientific Publications, 1975.

32. Kay AB. Allergy and allergic diseases. New England Journal of Medicine. 2001 Jan 4;344(1):307.

33. Wilson J, Karen R, Donald S, Peng LY, Joan D, Ross B, et al. Nasal histamine and heparin in chronic rhinitis: Ann Otol Rhinol Laryngol. 1988;94:389-92. 
34. Shekhar C, Sharan KK. Mast cells, eosinophils and goblet cells in nasal allergy. Indian J Otolaryngol. 1988;40(3):121-4.

35. White MV, Kaliner MA. Mediators of allergic rhinitis. J Allerg Clin Immunol. 1992;90(4):699704.
Cite this article as: Munjal M, Singh A, Khurana AS, Munjal S, Mehta A, Shukla K, et al. Role of plasma ascorbic acid in nasal allergy- a review. Int $\mathrm{J}$ Community Med Public Health 2020;7:4193-8. 